\title{
Altruism and selfishness of young ambitious people and sustainable consumption
}

\author{
Oksana Barsukova ${ }^{1}$, Natalia Mozgovaya ${ }^{1}$, Ludmila Kosikova ${ }^{1}$, and Natalia Lomova ${ }^{2, *}$ \\ ${ }^{1}$ Southern Federal University, B. Sadovay str., 105, Rostov-on-Don, Russia \\ ${ }^{2}$ Don State Technical University, Gagarin square, 1, Rostov-on-Don, Russia
}

\begin{abstract}
The paper presents the results of an empirical study of the orientation to altruism and the orientation to the selfishness of ambitious young people. All three phenomena studied manifest themselves in a person's social activity, in his relationship with other people. We see ambition as the desire of a person to become a significant person and to gain recognition of other people for real achievements. Altruism and ego is a certain attitude and behavior of a person, his interaction with other people. Altruism is a conscious and voluntary service to people, a desire to help other people, sympathy and collaboration. Selfishness is a person's preference and satisfaction with interests while neglecting the interests of others. The empirical study did not reveal significant differences in the representation and expression of altruism and selfishness among ambitious and unambiguous young people. The average score of altruism and selfishness in both groups of young people is in the range of averages, which suggests that both young people are equally inclined both to unselfishly help other people and to focus on personal interests. The results confirmed our assumption that ambitious people are different, and can be both altruistic and selfish. At the moment, the question of the unambitious characteristics of people who love them selves, who distinguish them from unambitious people, remains open and requires further study.
\end{abstract}

\section{Introduction}

The appeal to the study of altruism and selfishness among ambitious young people is due to the fact that the phenomena studied are formed, manifested and revived only in the social activity of a person, in his interaction with other people. In the modern world, the sphere of human social activity has been expanded. Just like with a person's life in the real world, a person has the opportunity to realize his activity in the virtual (digital) world. In the virtual world (as well as in the real one), a person strives to satisfy his need for significance and recognition, enters into relationships with other people.

The main desire of an ambitious person to gain recognition and become a significant person for other people for achievements $[1 ; 2]$. Ambition is a universal quality that does not depend, for example, on a person's gender and age, on their belonging to one generation or another [2], etc.

\footnotetext{
* Corresponding author: knesinka@mail.ru
} 
The ambitious aspiration of the person can be concretized in such purposes, such as, the power [3], glory and popularity, professional development and career development, etc. Thus, the ambitious aspiration can be satisfied only in communication and interaction of the person with other people. It assumes a certain attitude of the person towards other people [1]. As the relation and behavior, the expressing this relation, we suggest to consider altruism and egoism. The altruism and egoism are also shown and developed only in relationship of the person with other people [4].

Uncertainty of the concept "altruism" still remains in modern psychology. The authors dividing various concepts offer the definition. Nevertheless, in the most generalized understanding, the altruism is a care of the interests of other person. The term "altruism" was entered by $\mathrm{O}$. Comte who understood realization of the principle as altruism "to live for the sake of others", "to serve mankind, improving itself" [tsit. on 4]. The altruism is considered in psychology as criterion of moral behavior of the person, as the highest stage of moral personal development. This conscious, voluntary and disinterested service to people, desire to help people. In a basis of the relation and behavior in relation to other people sympathy, compassion lies. That is the altruism is caused by personal characteristics of the person (responsibility, feeling of duty, care, etc.). So Donald W. Pfaff understands altruism as human social impulse, it is the willingness to give without any expectation of reward [5].

Modern studies of altruism and altruistic behavior are devoted to the study of the genesis of altruism, types of altruism, social evaluation of altruism, etc. For example, modern studies of the "human-important" nature of altruism [6]. Another example, a study of the relationship to altruistic behavior shows that altruistic behavior is less than favored when the behavior deviates from social norms (norm deviation is evaluated negatively) [7]. Altruism is studied as an indicator of the attractiveness of a potential marriage partner [8]. "extraordinary" altruism [9], "sea-sonal (Christmas)" altruism [10] is studied. The association of altruism with various personal and behavioral characteristics is analyzed, for example, altruism and self-protection tendency [11], altruism and episodic future thinking [12]. Some contemporary psychological studies consider the relationship of social factors (for example, war) to the emergence of altruism [13].

And finally, the "eternal" question of altruism and selfishness as opposite qualities to each other, the percentage of altruism and selfishness "within" the person, the fact that one of these qualities does not exclude the other. As traditionally, altruism and selfishness are considered, opposing each other. For example, a recent study by Stefano Moroni [14]. Or, for example, a comparison of scientific concepts and conventional ideas about altruism and selfishness [15]

So selfishness, as a rule, is considered as a negative quality of a man. Selfishness is not just a person's concern for good. This is such a respect for one's interests when one infringes, neglects other people. This is the satisfaction of interests at the expense of other people, the person does not take into account what consequences this will have for others. Selfishness can be described as the consumer attitude and behavior of a person. At the same time, in other people, the egoist, first of all, sees negative features [4].

Modern investigations study the relationship of selfishness with the personal and cosocial-economic characteristics of a person. For example, wealth and a person's willingness to donate to charity [16]. Or how are the ties of happiness, selfishness and interpersonal strategies [17]? What is the relationship between trust, selfishness and interpersonal distance $[18]$ ?

\section{Materials and methods}

Our supposition is that it is wrong to give the same mark as to an altruist and as to an egoist. An ambitious man can be either altruist or egoist. 
Two tests were used at the empirical research: «Ambition» (O. Barsukova) and a test for the diagnosis of socio-psychological personality attitudes in the motivational-need sphere (O. Potemkina).

The object of empirical research - 94 young people (between the ages of 18 and 25).

\section{Results}

The ambition study identified two groups of young people:

Ambitious young people (70.21\%). This group includes young people who consider themselves ambitious and associate the implementation of ambitious loving aspirations with social advancement.

Unambitious young people (29.79\%). This group was composed of young people who do not evaluate themselves as ambitious, but they associate their cheerful aspirations, first of all, with higher education and career.

Next, indicators of orientation towards altruism and selfishness of ambition and unambitious young people were studied.

Ambitious young people:

Altruism orientation. The average score is 4.93 , which corresponds to the range of averages, the spread of points ranges from 0 - to 8 points. At the same time:

A low value of altruism was found in $12.1 \%$ of young people.

The average value of altruism is represented in most young people $-75.8 \%$.

A high rate of altruism was found in $12.1 \%$ of young people.

Selfish orientation. The average score is 4.09 , is in the range of averages, but borders on low values. Points range from 0 to 10 points. At the same time:

A low value of selfishness was found in about half of young people $-45.5 \%$.

The average rate of selfishness was found in more than a third of young people $-39.4 \%$.

A high indicator of selfishness was found in the minimum number of young people $15.2 \%$.

So ambitious young people have a focus on altruism and selfishness within the limits of average expression.

Unambitious young people:

Altruism orientation. The average score for the group is 5.28, which is in line with the range of averages, the spread of points is in the points range from 2 - to 9 points. At the same time:

A low value of altruism was found in the minimum number of young people $-7.1 \%$.

The average value of altruism is represented in most young people $-78.6 \%$.

A high rate of altruism was found in $14.2 \%$ of young people.

Selfish orientation. The average score is 4.92 , is in the range of averages, but borders on low values. Points range from 1 to 9 points. At the same time:

A low value of selfishness was found in more than half of young people $-57.1 \%$.

The average rate of selfishness was found in more than a third of young people $-35.7 \%$. $7.1 \%$.

A high indicator of selfishness was found in the minimum number of young people -

Thus, unambiguous youths have a focus on altruism and selfishness within the limits of average expression.

A comparative analysis of the representation of altruism and selfishness among ambitious and unambitiuos young people showed the following (table 1):

The average score for altruism orientation in both groups of students is inflated in the range of averages and is 4.93 points in ambitious young people and 5.28 points in unambitious young people. Obviously, no significant differences were found $(U=246,000$, $\mathrm{p}=0.05)$. 
The average self-orientation score in young people is also in the range of averages and is 4.09 points in ambitious young people and 4.92 points in unambitious young people. Obviously, no significant differences were found $(U=201,500, p=0.05)$.

Table 1. Orientation to the altruism and selfishness of ambitious and unambitious young people (average score).

\begin{tabular}{|l|c|c|c|}
\hline & $\begin{array}{c}\text { ambitious young } \\
\text { people }\end{array}$ & $\begin{array}{c}\text { unambitious young } \\
\text { people }\end{array}$ & $\begin{array}{c}\text { significance of } \\
\text { differences }\end{array}$ \\
\hline $\begin{array}{l}\text { Orientation to the } \\
\text { altruism }\end{array}$ & 4.93 & 5.28 & $\mathrm{U}=246.000 . \mathrm{p}=0.05$ \\
\hline Ego Orientation & 4.09 & 4.92 & $\mathrm{U}=201.500 . \mathrm{p}=0.05$ \\
\hline
\end{tabular}

A comparative analysis of the expression of the orientation towards altruism and selfishness of ambitious and unambitious young people showed the following (table 2):

Altruism orientation:

A low orientation towards altruism was found in a larger quantity of ambitious young people $(12.1 \%)$ compared to unambitious young people (7.1\%). But these differences are not significant $(\varphi=0.539, \mathrm{p}=0.05)$.

The average orientation towards altruism was revealed in almost equal quantities among non-ambitious young people (78.6\%) and ambitious young people (75.8\%). Obviously, these differences are not significant $(\varphi=0.210, \mathrm{p}=0.05)$.

A high focus on altruism was also found in almost equal quantities among unambitious young people (14.3\%) and ambitious young Leu Dei (12.1\%). Obviously, these differences are not significant $(\square=0.204, \mathrm{p}=0.05)$.

Thus, there were no significant differences in the expression of the orientation towards altruism among ambitious and unambitious young people. In both of their groups, most young people showed an average choice of altruism. In this case, it can be said that ambitious and unambitious young people are equally inclined to help others and can act to the detriment of themselves or the cause.

Selfish orientation:

A low orientation towards selfishness was found in more than half of unambitious young people $(57.1 \%)$ and in slightly less than half of ambitious young people $(45.5 \%)$. But these differences are not significant $(\varphi=0.727, \mathrm{p}=0.05)$.

The average orientation towards selfishness was found in almost equal quantities among ambitious young people (39.4\%) and among unambitious young people (35.7\%). Obviously, these differences are not significant $(\varphi=0.238, p=0.05)$.

A high focus on selfishness was also found in more quantity ambitious young people (15.2 per cent) than in unambitious s young people. But these differences are not significant $(\varphi=0.821, p=0.05)$.

So, there are no significant differences in the expression of the orientation towards egotism among ambitious and unambiguous young people. In both groups, the number of young people with a low severity of selfishness prevails. It can be said that both ambitious and unambitious young people are equally inclined to focus on personal interests.

So, there are no significant differences in the representation and severity of orientation to altruism and orientation to selfishness among ambitious and unambiguous young people.

Table 2. Focus on the altruism and selfishness of ambitious and unambitious young people. 


\begin{tabular}{|l|c|c|c|}
\hline & $\begin{array}{c}\text { Ambitious } \\
\text { young people }\end{array}$ & $\begin{array}{c}\text { Unambitious } \\
\text { young people }\end{array}$ & $\begin{array}{c}\text { Significance of } \\
\text { differences }\end{array}$ \\
\hline $\begin{array}{l}\text { Altruism } \\
\text { orientation: }\end{array}$ & & & \\
\hline low & $12.1 \%$ & $7.1 \%$ & $\varphi=0.539 . \mathrm{p}=0.05$ \\
\hline average & $75.8 \%$ & $78.6 \%$ & $\varphi=0.210 . \mathrm{p}=0.05$ \\
\hline high & $12.1 \%$ & $14.3 \%$ & $\varphi=0.204 . \mathrm{p}=0.05$ \\
\hline $\begin{array}{l}\text { Selfish } \\
\text { orientation: }\end{array}$ & & & \\
\hline low & $45.5 \%$ & $57.1 \%$ & $\varphi=0.727 . \mathrm{p}=0.05$ \\
\hline average & $39.4 \%$ & $35.7 \%$ & $\varphi=0.238 . \mathrm{p}=0.05$ \\
\hline High & $15.2 \%$ & $7.1 \%$ & $\varphi=0.821 . \mathrm{p}=0.05$ \\
\hline
\end{tabular}

\section{Discussion}

The results confirmed our assumption that one cannot unambiguously characterize an ambitious person as unambitious altruistic or selfish.

On the one hand, at the moment we are faced with the difficulty (or inability) to draw up a psychological portrait of an ambitious man and indicate the qualities that are inherent only in ambitious people and distinguish them from unambitious people.

On the other hand, perhaps the results obtained by us suggest the social flexibility of ambitious young people, the fact that they equally defend personal interests, as well as show selfless concern for other people.

\section{Conclusions}

Ambition as a motive is manifested in social activity aimed at gaining recognition and becoming a significant person for other people. Altruism is a social activity (prosocial behavior) that manifests itself in unselfish concern for the well-being of other people. Selfishness is human activity aimed at satisfying one's needs to the detriment of others.

Empirical research has confirmed our assumption that an ambitious person is different he can be altruistic or selfish, he can also be altruistic and selfish.

Our study found no significant differences in the presentation and expression of altruism orientation and selfish orientation among ambitious and unambitious young people. In both groups of young people, altruism and selfishness are in the range of averages.

We are going to plan to continue the theoretical and empirical study of the personal characteristics of ambitious young people who distinguish them from unambitious people.

\section{References}

1. E. Ilyin, The psychology of envy, hostility, vanity (Piter, SPb, 2014) ISBN 978-5-49600712-2

2. O. Barsukova, N. Mozgovaya, E. Scherbina et al., Innovative Technologies in Science and $\quad$ Education $\quad \mathbf{2 1 0} \quad$ (2020) https://doi.org/10.1051/e3sconf/202021020005

3. O. Barsukova, Journal of Process Management - New Technologies, International 8(1), 47-49 (2020) doi:10.5937/jouproman8-24622

4. E. Ilyin, Psychology of help. Altruism, selfishness, empathy (Piter, SPb, 2013) ISBN 9785-496-00234-9 
5. D.W. Pfaff, Origin of human socialization (Academic Press, 2020) https://doi.org/10.1016/C2020-0-02674-5

6. S. Taylor, Explore 15(5), 371-375 (2019)

7. Y. Kawamura, T. Kusumi, Journal of Experimental Social Psychology 90 (2020) https://doi.org/10.1016/j.jesp.2020.104021

8. L. Margana, M.S. Bhogal, J.E. Bartlett D. Farrelly, Personality and Individual Differences 137, 126-130 (2019) https://doi.org/10.1016/j.paid.2018.08.018

9. M.J. Crockett, P.L. Lockwood, Trends in Cognitive Science 22(12), 1071-1073 (2018)

10. M. Ekstrom, Journal of Economical Behavior and Organization 153, 177-193 (2018) https://doi.org/10.1016/j.jebo.2018.07.004

11. E.Y. Chan, Evolution and Human Behavior 38(5), 667-673 (2017) https://doi.org/10.1016/j.evolhumbehav.2017.05.004

12. R. Yi, A. Pickover, A.M. Stuppy-Sullivan et al., Journal of Experimental Social Psychology 65, 74-81 (2016) https://doi.org/10.1016/j.jesp.2016.03.005

13. J. Hall, D.T. Kahn, E. Skoog, M. Oberg, Journal of Experimental Social Psychology 94 (2021) https://doi.org/10.1016/j.jesp.2021.104101

14. S. Moroni, Cities 75, 81-89 (2018) https://doi.org/10.1016/j.cities.2018.01.004

15. R.W. Carlson, J. Zaki, Journal of Experimental Social Psychology 75, 36-40 (2018) https://doi.org/10.1016/j.jesp.2017.11.005

16. A.V. Whillans, E.M. Caruso, E.W. Dunn, Journal of Experimental Social Psychology 70, 242-250 (2017). https://doi.org/10.1016/j.jesp.2016.11.009

17. H.B. Tan, J.P. Forgas, Journal of Experimental Social Psychology 46(3), 571-576 (2010) https://doi.org/10.1016/j.jesp.2010.01.007

18. L.A. Rosenberg, M. Naef, C. Eisenegger, C. Lamm, Journal of Experimental Social Psychology 90 (2020) https://doi.org/10.1016/j.jesp.2020.104001 